\title{
Nitroglycerin-Sensitive and -Resistant Contractions Mediated by Receptor-Operated Calcium Channels in Rabbit Ear Artery
}

\author{
Yoshinobu AKIMOTO, Kazuyoshi KURAHASHI, \\ Hachiro USUI, Motohatsu FUJIWARA and Shoji SHIBATA* \\ Department of Pharmacology. Faculty of Medicine, Kyoto University, Kyoto 606. Japan \\ *Department of Pharmacology. School of Medicine. University of Hawaii. \\ Honolulu, Hawaii 96822 , U.S.A. \\ Accepted June 1, 1987
}

\begin{abstract}
In isolated rabbit ear arteries incubated in a $\mathrm{Ca}^{2+}$-free medium with EGTA and nifedipine in the presence of norepinephrine, serotonin or histamine, an addition of $\mathrm{Ca}^{2+}$ induced a tonic contraction which is due to $\mathrm{Ca}^{2+}$ entry through receptor-operated $\mathrm{Ca}^{2+}$ channels (ROCs). Nitroglycerin $\left(10^{-4} \mathrm{M}\right)$ significantly inhibited the ROCs-dependent contractions produced by serotonin or histamine, but failed to inhibit the ROCs-dependent contraction by norepinephrine. These results suggest the possible existence of two types of receptor-operated $\mathrm{Ca}^{2+}$ channels in rabbit ear artery.
\end{abstract}

Rabbit aorta is commonly used to distinguish between drugs acting on voltageoperated calcium channels (VOCs) and those acting at an intracellular level. The distinction is based on the known differences in events underlying contractions induced by potassium or by alpha adrenoceptor stimulation. Depolarization by potassium opens VOCs causing a sustained tonic contraction (1.2), whereas stimulation of alpha adrenoceptors causes a biphasic response, the first phase resulting from release of $\mathrm{Ca}^{2+}$ from intracellular stores and giving rise to the phasic component of the contraction (3. 4). Specific inhibitors of the calcium channel can be expected to block contractions induced by depolarization, but not to inhibit the phasic contraction induced by alpha-adrenoceptor agonists. The second component of the contractile response to alpha adrenoceptor stimulation in aortic preparations is thought to result from the movement of extracellular $\mathrm{Ca}^{2+}$ through ROCs which

\footnotetext{
$\dagger$ This study was supported in part by Grants-in-Aid for Developmental Scientific Research (60870010) and for Specia! Project Research (61232007) from the Ministry of Education. Science and Culture. Japan.
}

gives rise to a sustained tonic contraction (5-8). There is substantial evidence to suggest that alpha receptor-controlled influx of $\mathrm{Ca}^{2+}$ through $\mathrm{ROCs}$ is additive to that induced by depolarization and is less sensitive to blockade by calcium channel in hibitors than $\mathrm{Ca}^{2+}$ influx through VOCs (9) Nitroglycerin is widely used as a coronary dilator in the treatment of angina, and it has been reported that nitroglycerin does not affect the influx of $\mathrm{Ca}^{2+}$, but accelerates the extrusion of $\mathrm{Ca}^{2+}$ in cultured vascular cells (10). It was, therefore of interest to see what effects nitroglycerin might have on ROCs. The present experiments were undertaken to elucidate the effects of nitroglycerin, in rabbit ear artery, on ROCs-mediated contractions in response to different receptor agonists such as norepinephrine, serotonin or histamine in a $\mathrm{Ca}^{2+}$-free medium containing EGTA and nifedipine. The results suggested the presence of both nitroglycerin-sensitive ROCs that are activated by serotonin and histamine and nitroglycerin-resistant ROCs that are activated by norepinephrine.

Rabbits of either sex, weighing 3.0 to 3.5 $\mathrm{kg}$. were anesthetized with an intraperitoneal injection of pentobarbital sodium (25 $\mathrm{mg} / \mathrm{kg}$ ) and sacrificed by bleeding from the common 
carotid artery. The ear was rapidly removed and the ear artery was isolated. The arteries were helically cut into strips of about $20 \mathrm{~mm}$ long and $2 \mathrm{~mm}$ wide. The specimen was vertically fixed between hooks in an organ bath containing the nutrient solution. which was maintained at $37 \pm 0.5^{\circ} \mathrm{C}$ and aerated with a mixture of $95 \% \mathrm{O}_{2}$ and $5 \% \mathrm{CO}_{2}$. The hook anchoring the upper end of the strips was connected to the lever of a forcedisplacement transducer (San-Ei Sokki Co., Tokyo, Japan). The resting tension was adjusted to $0.5 \mathrm{~g}$. The solution consisted of $120 \mathrm{mM} \mathrm{NaCl}, 4.7 \mathrm{mM} \mathrm{KCl}, 1.2 \mathrm{mM} \mathrm{MgSO}_{4}$, $1.2 \mathrm{mM} \mathrm{KH}_{2} \mathrm{PO}_{4}, 2.5 \mathrm{mM} \mathrm{CaCl} .25 \mathrm{mM}$ $\mathrm{NaHCO}_{3}$ and $10 \mathrm{mM}$ glucose. The $\mathrm{pH}$ of the solution was 7.2 to 7.4. Before the experiments were begun, preparations were allowed to equilibrate for 90 to $120 \mathrm{~min}$ in the organ bath, during which period the bathing media were replaced every $15 \mathrm{~min}$. Isometric contractions were recorded on an ink-writing oscillograph (San-Ei Sokki Co., Tokyo, Japan). The isometric tension developments resulting from activation of ROCs by norepinephrine, serotonin and histamine were compared by the following experimental procedures. In normal medium, the contractions produced by norepinephrine, serotonin and histamine at concentrations producing a maximal contraction were determined as a $100 \%$ control. Then, to measure ROCs-mediated contractions, tissues were incubated for $25 \mathrm{~min}$ in a $\mathrm{Ca}^{2+}{ }_{-}$free medium containing EGTA $(0.1 \mathrm{mM})$ and nifedipine $\left(10^{-6} \mathrm{M}\right)$ before an addition of $\mathrm{Ca}^{2+}(2.5 \mathrm{mM})$. An agonist was introduced to the bath $15 \mathrm{~min}$ prior to the $\mathrm{Ca}^{2+}$ application. and nitroglycerin was added to the bath 10 min before the addition of $\mathrm{Ca}^{2+}$.

As shown in Fig. 1, the contractions produced by norepinephrine, serotonin and histamine (all at $10^{-5} \mathrm{M}$ concentrations resulting in maximal contractions) in normal medium were $3.8 \pm 0.3 \mathrm{~g}(n=5), 2.6 \pm 0.3 \mathrm{~g}$ $(n=6)$ and $3.6 \pm 0.6 \mathrm{~g}(n=5)$, respectively. After incubation of the tissue in a $\mathrm{Ca}^{2+}$-free medium containing EGTA and nifedipine for $10 \mathrm{~min}$, agonists such as norepinephrine. serotonin or histamine caused a transient contraction, and the second application of these agonists failed to cause contraction.

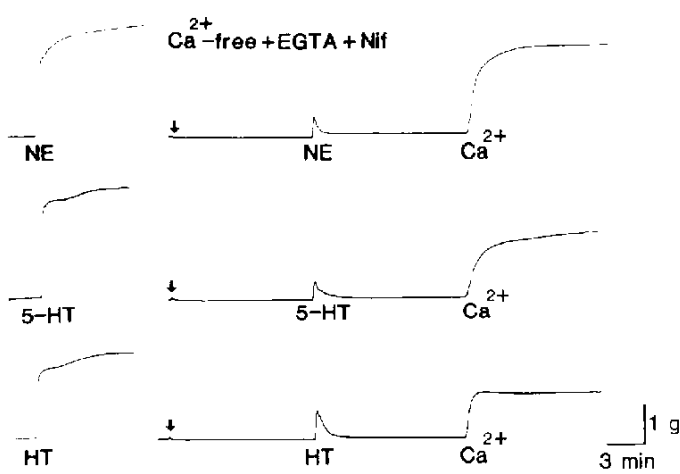

Fig. 1. ROCs-dependent contractions produced by norepinephrine, serotonin and histamine in rabbit ear artery. The contractions on the left side were in normal medium. ROCs-dependent contractions produced by norepinephrine $\left(10^{-5} \mathrm{M}\right)$, setoronin $\left(10^{-5}\right.$ $\mathrm{M})$ and histamine $\left(10^{-5} \mathrm{M}\right)$ were obtained by the addition of $\mathrm{Ca}^{2+}(2.5 \mathrm{mM})$ in the $\mathrm{Ca}^{2+}$-free medium containing EGTA $(0.1 \mathrm{mM})$ and nifedipine $\left(10^{-6}\right.$ $M)$. The details of the procedure were described in the Text.

The $\mathrm{Ca}^{2+}$-induced contractions in the presence of norepinephrine $\left(10^{-5} \mathrm{M}\right)$. serotonin $\left(10^{-5} \mathrm{M}\right)$ or histamine $\left(10^{-5} \mathrm{M}\right)$ in $\mathrm{Ca}^{2+}$-free medium containing EGTA $(0.1$ $\mathrm{mM})$ and nifedipine $\left(10^{-6} \mathrm{M}\right)$ were $2.9 \pm 0.3$ $\mathrm{g}(n=5), 1.2 \pm 0.2 \mathrm{~g}(\mathrm{n}=6)$ and $1.5 \pm 0.2 \mathrm{~g}$ $(n=5)$, respectively (Fig. 1). The contribution of ROCs to the contraction appeared to be largest in the case of norepinephrine, $76 \%(n=5)$, and it was only $46 \%$ $(n=6)$ and $42 \%(n=5)$ in the serotonin- and histamine-induced contractions, respectively. The inhibitory effects of nitroglycerin on these ROCs are summarized in Table 1. The activation of ROCs by norepinephrine was nearly insensitive to nitroglycerin even at $10^{-4} \mathrm{M}$. On the other hand, the activation of ROCs by serotonin and histamine was inhibited by nitroglycerin in a concentrationdependent fashion $\left(10^{-6}\right.$ to $\left.10^{-4} \mathrm{M}\right)$. At a concentration of $10^{-4} \mathrm{M}$. nitroglycerin inhibited serotonin- and histamine-induced ROCs-dependent contractions by $79 \%(n=6)$ and $73 \%(n=5)$, respectively.

Substantial evidence has been accumulated which suggests that receptor-controlled influx of $\mathrm{Ca}^{2+}$ through $\mathrm{ROCs}$ is less sensitive to blockade by calcium channel inhibitors than $\mathrm{Ca}^{2+}$ passing through VOCs 
Table 1. Inhibitory effects of nitroglycerin on ROCs-dependent contractions produced by norepinephrine, serotonin and histamine in rabbit ear artery

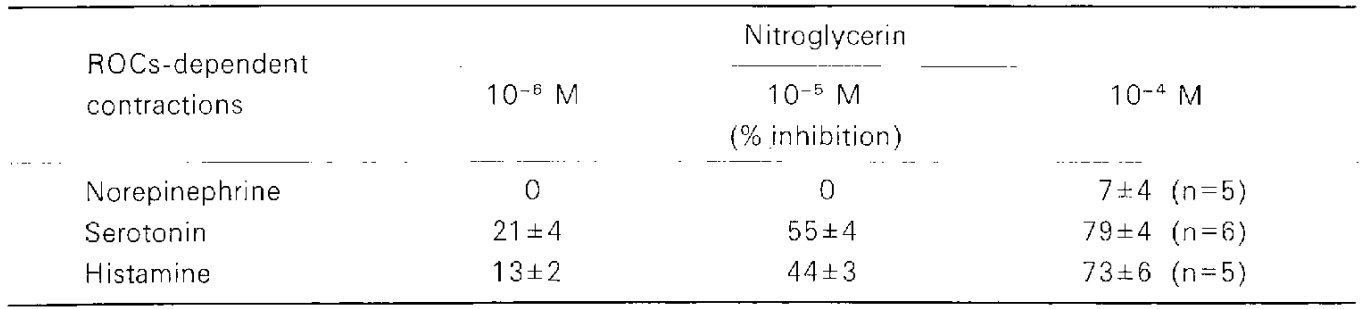

The ROCs-dependent contractions produced by norepinephrine $\left(10^{-5} \mathrm{M}\right)$, serotonin $\left(10^{-5} \mathrm{M}\right)$ and histamine $\left(10^{-5} \mathrm{M}\right)$ were obtained by the addition of $\mathrm{Ca}^{2+}(2.5 \mathrm{mM})$ in the $\mathrm{Ca}^{2+}$-free medium containing EGTA $(0.1 \mathrm{mM})$ and nifedipine $\left(10^{-6} \mathrm{M}\right)$ (see Text). The ROCs-dependent contractions in the absence of nitroglycerin were regarded as the control (100\%).

(2, 9). The present experiments examined the degree of involvement of ROCs in the contractions produced by norepinephrine, serotonin and histamine in rabbit ear artery, and examined the inhibitory effects of nitroglycerin on those ROCs. There were clear differences in the involvement of ROCs in norepinephrine, serotonin and histamineproduced contractions. The order of involvement of ROCs in the contractions was norepinephrine $(76 \%)>$ serotonin $(46 \%) \cdot$ histamine $(42 \%)$. This result indicates that the degree of activation of ROCs by these receptors agonists is different. Assuming that the contractile response to $\mathrm{Ca}^{2+}$ added to the $\mathrm{Ca}^{2+}$-free medium reflects the proportion of ROCs contributing to the contraction, nearly $76 \%$ of the channels responding to norepinephrine in a maximal contraction are ROCs, while in the case of serotonin and histamine, the ROCs appear to contribute less than in the case of norepinephrine.

Recently, Shibata and Satake have reported that nitroglycerin inhibited the $\mathrm{Ca}^{2+}$ response in the presence of clonidine in the renal and femoral arteries. In rabbit renal and femoral arteries, this $\mathrm{Ca}^{2+}$ response is assumed to be almost completely due to specific receptor-activated $\mathrm{Ca}^{2+}$-entry independently of voltage-dependent $\mathrm{Ca}^{2+}$ entry (11). Nitroglycerin had no effect on the response of ROCs to norepinephrine, although it did inhibit their responses to serotonin and histamine. These results indicate that nitroglycerin may have specific effects on some, but not all ROCs. It has been shown that nitroglycerin does not affect $\mathrm{Ca}^{2+}$ influx, but does activate extrusion of intracellular free $\mathrm{Ca}^{2+}$, resulting in vasodilation (10). If this is the case, it may be that in rabbit ear artery, nitroglycerin causes the extrusion of cellular $\mathrm{Ca}^{2+}$ to serotonin and histamine but not to norepinephrine. Although, from the present experiments, the precise mechanisms for the inhibitory effects of nitroglycerin on ROCs in response to norepinephrine, serotonin and histamine are not fully explicable, the mechanisms underlying calcium mobilization activated by norepinephrine definitely seem to be different from those responsible for mobilization of calcium activated by serotonin receptors and histamine receptors.

\section{References}

1 Weiss, G.B.: Calcium and contractility in smooth muscle. In Advances in General and Cellular Pharmacology, Edited by Narahashi, T. and Bianchi, C.P., p. 71-154, Plenum, New York (1977)

2 Bolton, T.B.: Mechanisms of action of transmitters and other substances on smooth muscle. Physiol. Rev. 59, 606-718 (1979)

3 Deth, R. and Van Breemen, C.: Relative contributions of $\mathrm{Ca}^{2+}$ influx and celiular $\mathrm{Ca}^{2+}$ release during drug induced activation of the rabbit aorta. Pflügers Arch. 348, 13-22 (1974)

4 Deth, R. and Van Breemen, C.: Agonist induced release of intracellular $\mathrm{Ca}^{2+}$ in the rabbit aorta. J. Membr. Biol. 30, 363-380 (1977)

5 Cauvin, C., Loutzenhiser, R., Hwang, O. and Van Breemen, C.: $\alpha_{1}$-Adrenoceptors induce $\mathrm{Ca}$ influx and intracellular $\mathrm{Ca}$ release in isolated rabbit aorta. Eur. J. Pharmacol. 84, 233-235 (1982) 
6 Cauvin, C. and Malik, S.: Induction of $\mathrm{Ca}^{2+}$ influx and intracellular $\mathrm{Ca}^{2+}$ release in isolated rat aorta and mesenteric resistance vessels by norepinephrine activation of alpha-1 receptors. J. Pharmacol. Exp. Ther. 230, 413-418 (1984)

7 Hester, R.K.: Effects of 2-nicotinamidoethyl nitrate on agonist-sensitive $\mathrm{Ca}^{2+}$ release and $\mathrm{Ca}^{2+}$ entry in rabbit aorta. J. Pharmacol. Exp. Ther. 233, 100-111 (1985)

8 Shibata, S., Satake, N., Ueda, S., Hester, R.K. and Flores, F.: Effects of nicorandil N-(2hydroxyethyl) nicotinamide nitrate, a new antiangina agent, on the contractile responses to $\alpha_{1}$ and $\alpha_{2}$-adrenoceptor agonists in isolated rabbit aorta. Blood Vessels 23, 246-256 (1986)
9 Meisheri, K.D., Hwang, O. and Van Breemen, C.: Evidence for two separate $\mathrm{Ca}^{2+}$ pathways in smooth muscle plasmalemma. J. Membr. Biol. 59, 19-25 (1981)

10 Kobayashi, S., Kanaide, $H$. and Nakamura, M.: Cytosolic-free calcium transients in cultured vascular smooth muscle cells: microfluorometric measurements. Science 229, 553-556 (1985)

11 Shibata, S. and Satake, N.: Differential inhibitory effects of nicorandil, a new anti-angina agent, on the contractile responses to alpha-1 - and alpha2 -adrenoceptor agonists in isolated rabbit renal and femoral arteries. Pharmacology (1987) (in press) 